\title{
Socioeconomic variations in the use of common surgical operations
}

\author{
ANGELA COULTER, KLIM MCPHERSON
}

\begin{abstract}
The surgical experience of a sample of people aged 40-64 randomly selected from general practice lists was elicited by means of a postal questionnaire and the results examined in relation to two indicators of socioeconomic status. Eighty per cent of the sample had had one or more surgical operations and women had a higher mean number of operations than men. Those in the more advantaged groups had a higher mean number of operations than those in the less advantaged groups. This difference was, however, mainly accounted for by operations carried out in childhood before the establishment of the National Health Service and by private sector surgery.
\end{abstract}

\section{Introduction}

There are considerable regional variations between the age and sex standardised surgical rates for different countries, which do not appear to accord with known differences in morbidity. For instance, women in the United States are about three times as likely to undergo hysterectomy at any age as women in this country. ${ }^{1}$ Similarly, cholecystectomy is four times as common in Canada as in Britain. ${ }^{2}$

Most research in this area has concluded that non-medical factors are as important as medical ones in determining surgical rates, but there is debate about the relative influence of the various nonmedical factors that have been identified. The measurement of morbidity is generally problematic, ${ }^{3}$ and it is therefore difficult to

\footnotetext{
University Department of Community Medicine and General Practice, Gibson Building, Radcliffe Infirmary, Oxford OX2 6HE

A COULTER, BA, research officer

$\mathrm{K}$ MCPHERSON, PHD, university lecturer in medical statistics

Correspondence to: Dr K McPherson.
}

relate independent measures of disease incidence to the rates at which common surgical operations are performed. One attempt to do this by using necropsy data found that the existence of gallstones is the strongest determinant of cholecystectomy rates within the National Health Service, although not the sole determinant. ${ }^{4}$ Many other studies have, however, shown that supply factors, such as the availability of hospital beds, staffing levels, and methods of payment, in conjunction with physicians' practice styles, influence surgical rates and explain much of the variation. ${ }^{56}$

Apart from the study of cholecystectomy rates, the demand for surgery has been relatively unexplored. In addition to morbidity, demand is affected by patients' beliefs about health, their attitudes to seeking help, and their perceptions of surgery, which are shaped by cultural norms and attitudes and influenced by those members of the medical profession with whom they come into contact. Disentangling these various factors and measuring the extent to which they may influence clinical decision making is not straightforward, but as a first step we decided to study the relation between socioeconomic status and surgical rates.

The existence of social class differences in the rates at which various operations are performed, independent of known class differences in morbidity, could be one possible manifestation of the patient's influence on the decision making process. Occupational data are not routinely collected in relation to hospital inpatient statistics, and there have been few attempts to relate social class to surgical rates, exceptions being studies of surgery undergone in childhood such as tonsillectomy and circumcision, for which clear positive social class gradients have been found. ${ }^{78}$

\section{Subjects and methods}

After the approval of the Central Oxford Ethics Committee and the Oxford Section of Surgery had been obtained and with the active collaboration of several local general practitioners, a questionnaire was sent to 6014 people aged 40-64 randomly selected from the age sex registers of eight general practices in the Oxford region. 
The questionnaire was designed to elicit a complete surgical history with detailed questions on the most common surgical operations (tonsillectomy, appendicectomy, hernia repair, varicose veins procedures, thyroidectomy, sterilisation, prostatectomy, circumcision, dilatation and curettage, hysterectomy oophorectomy, and operations on the breast) including reasons for surgery, length of stay and waiting times, age at operation, and method of payment. Respondents were also asked to provide information on various measures of social status, including their own, their partner's, and their father's occupation and employment status, the age at which they completed their full time education, type of secondary school attended, highest educational qualification obtained, and housing tenure.

Statistical analysis was performed on indirectly standardised rates using $\chi^{2}$ tests for trend.

\section{Results}

\section{QUESTIONNAIRE RESPONSE}

After two reminders had been sent 4120 completed questionnaires were returned, 441 questionnaires were returned undelivered because the addressee had moved away or died, and 34 respondents had to be deleted because they were outside the age range. Completed questionnaires were thus received from $74 \cdot 4 \%$ of the sample (after allowing for these deletions). The response from women $(77 \cdot 1 \%)$ was slightly better than that from men $(71.6 \%)$, but there was little variation in the response from the different practices, despite the fact that their social class composition varied considerably.

A list of non-respondents was examined by staff at one of the practices. Of the 67 non-respondents, 38 were not known to any of the staff and a large proportion of these were presumed to have moved out of this relatively mobile inner city practice area. One patient had died, and, of the remainder, six in social classes IV or V. This was very similar to the social class distribution of respondents from this practice, $21 \%$ of whom were in social classes I and II, $44 \%$ in social class III, and $29 \%$ in social classes IV and V. The surgical histories of non-responders and responders, as recorded in the notes, were compared, and the mean number of operations per person was found to be the same for both groups of men at 0.8 but slightly lower for female non-responders at $1 \cdot 1$ than responders at $1 \cdot 7$. (These are lower than the mean numbers reported below because childhood surgery is underrecorded in the notes.) On this evidence we conclude that non-response bias did not affect these results to any appreciable extent.

A further potential disadvantage of our method of collecting surgical histories is that it is dependent on patients' knowledge and recall of their surgical histories. We attempted to validate the data (to be published elsewhere ${ }^{9}$ ) by checking a sample of the histories obtained in our survey against general practitioner records. The results were reassuring as they showed no major discrepancies, and it thus seems reasonable to assume that surgical histories are in general well remembered.

In the results that follow, rates for most common surgical operations are presented in relation to two measures of social status: social class based on occupation, as measured by the Registrar General's scale, and age at completion of full time formal education. Married women are assigned a Registrar General's classification according to their husband's present or most recent full time occupation. Rates for operations commonly undergone appendicectomy) are allocated a Registrar General's classification according to the father's occupation when the respondent was aged 14 .

Table I shows the association between these variables, from which it is clear that, although there is a strong relation between them, they discriminate in different ways. The disadvantages of the Registrar General's classification as a means of classifying women are well known, ${ }^{10}$ and the use of alternative measures of socioeconomic status is often recommended. ${ }^{\prime \prime}$

Both occupation and education taken alone are imperfect measures of social status or material position, but in the absence of an ideal index it seemed worthwhile to compare the results produced when surgical histories are examined in relation to both of these indicators. six were classified as being in social classes I or II, 16 in social class III, and in childhood or adolescence (namely, circumcision, tonsillectomy, and

\section{SURGICAL HISTORIES}

Between them, the 4120 respondents in this survey, who were evenly spread through the age groups 40-64 (mean age for each sex was 51.6 years), reported a total of 8260 surgical operations, excluding obstetric operations Women had a higher mean number of operations per person $(2 \cdot 2)$ than men $(1 \cdot 8)$, but if sex specific operations are excluded (for example, prostatectomy, hysterectomy, dilatation and curettage, oophorectomy, etc) the means are the same for both sexes at 1.3 operations per person. Figure shows the total number of operations per person. Only $20 \%$ of the sample had had no surgical operations. Nearly half had had one or two operation and a third had had three or more.

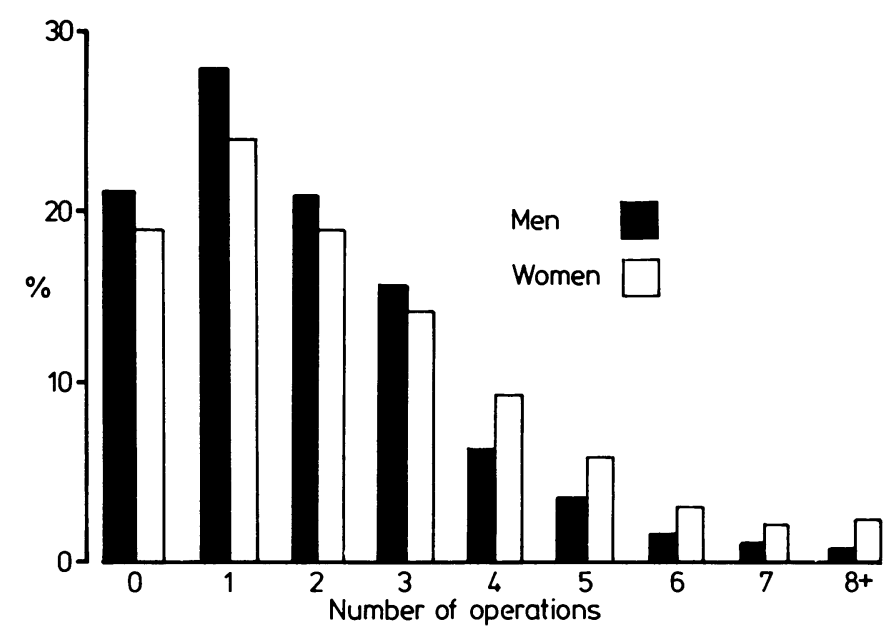

FIG 1-Total number of operations per person.

TABLE II - Most common operations in order of frequency

\begin{tabular}{lccc}
\hline & \% Men & \% Women & \% Total \\
\hline Dilatation and curettage & - & $35 \cdot 2$ & $35 \cdot 2$ \\
Tonsillectomy & $33 \cdot 4$ & $34 \cdot 7$ & $34 \cdot 1$ \\
Circumcision & $27 \cdot 9$ & - & $27 \cdot 9$ \\
Hysterectomy & - & $18 \cdot 7$ & $18 \cdot 7$ \\
Appendicectomy (excluding incidental operations) & $13 \cdot 9$ & $16 \cdot 0$ & $14 \cdot 5$ \\
Sterilisation (men and women) & $14 \cdot 6$ & $10 \cdot 3$ & $12 \cdot 3$ \\
Breast operations & $11 \cdot 2$ & $7 \cdot 5$ & $7 \cdot 5$ \\
Hernia repair & $3 \cdot 3$ & $6 \cdot 5$ & $6 \cdot 6$ \\
Varicose veins & $1 \cdot 6$ & $4 \cdot 4$ & $4 \cdot 9$ \\
Cholecystectomy & - & $2 \cdot 4$ & $3 \cdot 1$ \\
Oophorectomy & $0 \cdot 8$ & $2 \cdot 1$ & $1 \cdot 4$ \\
Thyroidectomy & $0 \cdot 3$ & - & $0 \cdot 3$ \\
Prostatectomy & & & \\
\hline
\end{tabular}

Table II shows the proportion of those at risk who had had each of the most common operations. Dilatation and curettage was the most commonly occurring operation with $35 \%$ of all female respondents having undergone at least one dilatation and curettage (one third of these had had the operation more than once). Over a third of the sample had had their tonsils removed, the rates for men and women being very similar. Incidental appendicectomies (that is, appendices removed at the same time as another operation) have been excluded from the analyses, but even after these exclusions women underwent more appendicectomies than men. Male sterilisation (vasectomy) had been undergone by nearly $15 \%$ of the men in the sample and was more common than female sterilisation. Hernia repair was more common among men and cholecystectomy more common among women.

When the data were broken down by the two measures of socioeconomic TABLE I-Social class in relation to age at completion of full time education. Figures are numbers of subjects

\begin{tabular}{|c|c|c|c|c|c|c|c|c|c|c|}
\hline \multirow[b]{2}{*}{ Terminal education age } & \multicolumn{5}{|c|}{ Current social class } & \multicolumn{5}{|c|}{ Father's social class } \\
\hline & I and II & III & IV and $V$ & Unclassifiable & Total & I and II & III & IV and $V$ & Unclassifiable & Total \\
\hline$\geqslant 19$ & 453 & 44 & 3 & 12 & 512 & 279 & 146 & 31 & 56 & 512 \\
\hline $16-18$ & 673 & 321 & 76 & 67 & 1137 & 392 & 459 & 114 & 172 & 1137 \\
\hline \multirow{3}{*}{ Not known } & 502 & 1112 & 496 & 172 & 2282 & 235 & 990 & 656 & 401 & 2282 \\
\hline & 42 & 54 & 31 & 62 & 189 & 25 & 44 & 36 & 84 & 189 \\
\hline & 1670 & 1531 & 606 & 313 & 4120 & 931 & 1639 & 837 & 713 & 4120 \\
\hline
\end{tabular}


status interesting differences emerged (table III). Those in the more advantaged social groups had a higher mean number of operations per person than those in the less advantaged groups. Differences between the highest and lowest socioeconomic category are significant at 5\% for each sex and each measure. Differences between sexes pooled over categories are significant at $1 \%$.

\begin{tabular}{|c|c|c|}
\hline Category & Men & Women ${ }^{\star}$ \\
\hline $\begin{array}{l}\text { Social class: } \\
\text { I and II } \\
\text { III } \\
\text { IV and V }\end{array}$ & $\begin{array}{ll}2.00 & (859) \\
1.78 & (700) \\
1.71 & (282)\end{array}$ & $\begin{array}{ll}2 \cdot 38 & (811) \\
2 \cdot 09 & (831) \\
2 \cdot 06 & (323)\end{array}$ \\
\hline $\begin{array}{l}\text { Terminal education age } \\
\geqslant 19 \\
16-18 \\
<16\end{array}$ & $\begin{array}{l}2.08(306) \\
1.94(493) \\
1.78(1063)\end{array}$ & $\begin{array}{ll}2 \cdot 37 & (206) \\
2 \cdot 38 & (644) \\
2 \cdot 09 & (1218)\end{array}$ \\
\hline
\end{tabular}

^Excluding obstetric operations.

The data were then examined to see if there was variation in the age standardised rates for specific operations according to the two indicators. Only those operations undergone by more than $5 \%$ of men or women at risk are given here.

Tonsillectomy and circumcision-The childhood operations, tonsillectomy and circumcision, showed clear positive gradients on both measures (fig 2). Among men the gradients are significant at $1 \%\left(\chi^{2}\right.$ trend, circumcision 18.9 and $41 \cdot 7$, tonsillectomy $31 \cdot 2$ and $46 \cdot 3$ ) for women terminal education age
A higher proportion of those in the more advantaged groups had been private patients for this operation, and altogether $8 \%$ of the hernia repairs were undergone privately.

Varicose veins operations-Fifteen per cent of all varicose veins operations were carried out privately. When NHS operations are considered alone, a negative terminal educational age gradient is apparent among women (fig $3 c$ ), who were twice as likely to have had the operation as men.

Vasectomy and female sterilisation-The differences between the most advantaged groups and those least advantaged were negligible when the rates for vasectomy and female sterilisation were considered (fig $3 d$ ). This is particularly interesting in the case of vasectomy since this operation had the greatest proportion of private surgery, at $68 \%$ of all vasectomies. This operation is not now routinely available on the NHS in the Oxford regional health authority, which accounts for the high proportion of private surgery (usually carried out on a day patient basis). The remaining third of the vasectomies were, however, NHS operations, and these show, if anything, a gradient in favour of the least advantaged.

Breast operations-The age and parity standardised rates for female breast operations were higher for social classes I and II than for those in social classes IV and V (fig $3 e)\left(\chi^{2}=4 \cdot 9, p<0 \cdot 05\right)$. Ten per cent of these operations were carried out on private patients.

Dilatation and curettage and hysterectomy-No clear pattern was apparent in the overall rates for either operation. For both, the two indicators appear to discriminate in different ways, the rates for dilatation and curettage being high in social classes IV and $\mathrm{V}$ but also among those who had received higher education $\left(\chi^{2}=4 \cdot 01, \mathrm{p}<0.05\right)$ (fig $3 f$ ). Hysterectomy rates were high among those leaving school at the statutory leaving age, but there were no social class differences (fig $3 g$ ). When NHS operations are considered alone, however, a negative gradient is fairly clearly apparent for both of these gynaecological operations. Fourteen per cent of the hysterectomies and $8 \%$ of the dilatations and curettages were undergone privately, with the private surgery being concentrated in the most advantaged groups.
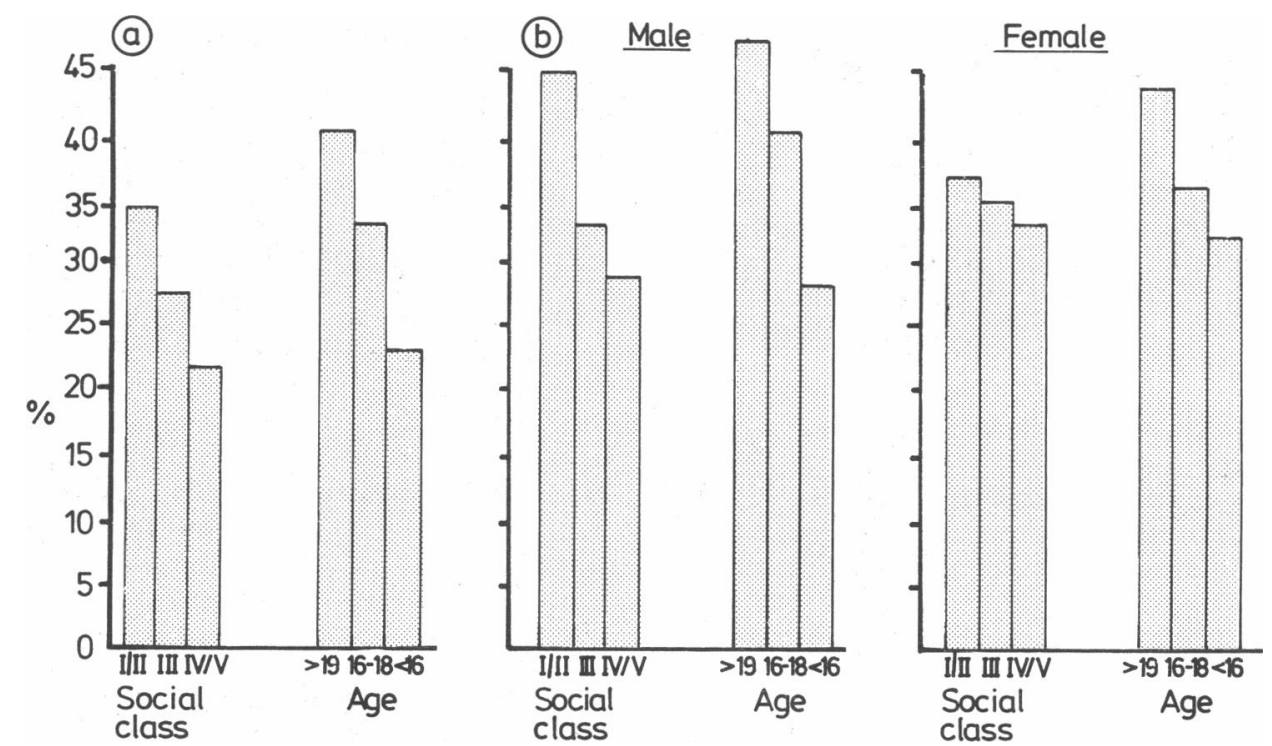

FIG 2-Percentage of children undergoing ( $a$, circumcision and $(b)$ tonsillectomy according to social class and age at completion of full time education.

discriminated more clearly than social class $\left(\chi^{2}\right.$ trend $\left.10 \cdot 2, p<0 \cdot 01\right)$. The mean age at tonsillectomy was 10 years old, and $90 \%$ of all the circumcisions were undergone at under 5 years of age. Since respondents to this survey were born between 1919 and 1943 the vast majority of these childhood operations were carried out before the establishment of the NHS in 1948.

Appendicectomy-The pattern for appendicectomy-an operation commonly undergone by adolescents and young adults (mean age for this operation was 23 years)-was more complex (fig $3 a$ ). Clear gradients are apparent for men as measured by their father's social class and for women as measured by their age at completion of full time education $\left(\chi^{2}=7 \cdot 4, p<0 \cdot 01\right.$ and $\chi^{2}=10.3, p<0.01$ respectively). Five per cent of the appendicectomies were carried out privately, the smallest proportion of all the operations studied.

Hernia repair showed the opposite pattern, particularly among male respondents, who were more than four times as likely to have undergone the operation than women (fig $3 b$ ). The inverse gradient is clear on both measures when only those operations carried out in the NHS are considered.

\section{Discussion}

If the experience of respondents in this survey of residents of the Oxford region is typical the majority of British people can expect to have undergone at least two surgical operations by the time they reach middle age. If, therefore, those in the most advantaged groups are consuming an excess of surgical resources relative to need it should be a matter of concern to all those concerned with monitoring resource distribution within the NHS.

On initial examination, the data presented by this survey are worrying in this regard since they show inequalities in the use of surgical services, with more advantaged groups (as measured by both indicators) having higher overall rates of surgery than those in the least advantaged groups. On closer examination, however, it becomes apparent that much of this excess is accounted for by operations carried out when members of this sample were children 
and therefore before or in the early days of the establishment of the NHS.

The rates for circumcision cannot be related to any measure of need since the operation in children is rarely carried out in response to clinically defined indications. The circumcision rates are therefore likely to be mainly a function of demand from patients (or, rather, parents) and these data suggest that in the 1920s and 1930s circumcision was more popular among the higher socioeconomic groups. (Only 14 respondents described themselves as Jewish or Muslim, which suggests that the gradient is not related to religious affiliation.)
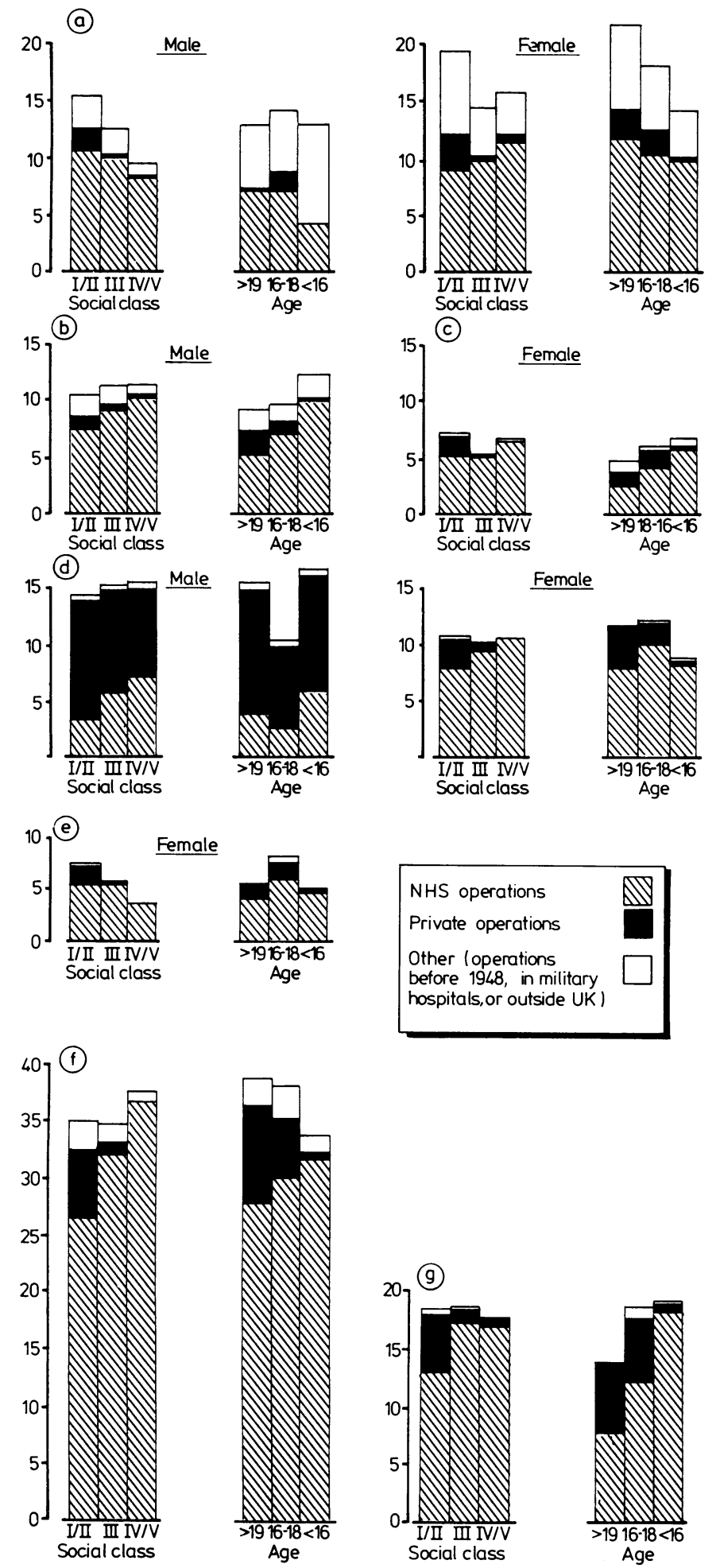

FIG 3-Percentage of subjects undergoing (a) appendicectomy, $(b)$ hernia repair, $(c)$ varicose veins, $(d)$ sterilisation, $(e)$ breast operations, $(f)$ dilatation and curettage, and $(g)$ hysterectomy according to social class and age at completion of full time education. Rates for men are standardised for age, those for women for age and parity.
Interestingly, tonsillectomy, the other operation commonly $\frac{\text { W }}{2}$ carried out in childhood, is subject to the same level of social class variation, particularly among male patients who have had the $\varrho$ operation. This finding is compatible with those from other studies and reinforces the view that tonsillectomy, like circumcision, was $\cong$. carried out at least in part in response to demand from middle class parents. ${ }^{12}$ There is no evidence of a positive social class gradient in $\mathbb{\infty}$ the incidence of upper respiratory tract infections, and tonsil-m lectomy is nowadays carried out much less frequently than in the past.

Children of parents in social classes I and II in this sample also $\stackrel{\overrightarrow{\vec{S}}}{\stackrel{\vec{\rho}}{.}}$ underwent more appendicectomies than those in the other groups. This pattern of social class variation in appendicectomy rates has been found before, ${ }^{13}$ but it is, nevertheless, surprising in an $\frac{\bar{T}}{\sqrt{0}}$ operation largely carried out for acute conditions. If the incidence of $\stackrel{\mathbb{Q}}{\varrho}$ appendicitis is affected by diet then social class differences in dietary habits may be responsible. ${ }^{14}$ A proportion of these appendi- $\rightarrow$ cectomies may, however, have been carried out for undiagnosed $\stackrel{\circ}{-}$ abdominal pain, which may or may not have been confirmed $\vec{\omega}$ as appendicitis after surgery. In this case, patient pressure or $\stackrel{\mathscr{D}}{\mathscr{D}}$ differential selection for surgery could have influenced the $\frac{\partial}{3}$ appendicectomy rates and might therefore be responsible for the social class differences seen here.

The inverse social class gradient in hernia repair operations is consistent with the plausibly greater risk of inguinal hernia among $\underset{\infty}{\infty}$ those employed in manual occupations, or with a lesser ability to cope with untreated hernias. The diagnosis of this condition is less $\overrightarrow{\mathscr{C}}$ susceptible to variations in clinical judgment than many of the othero indications for surgery discussed here, but the availability of an alternative form of conservative treatment allows room for patient 0 involvement in the decision making process for this operation. $\subseteq$ Unfortunately, we do not have data on those patients who opted to use a truss rather than undergo surgery, but this gradient is $\vec{\oplus}$ consistent with standardised consulting ratios reported in the or National Morbidity Survey. ${ }^{15}$

The only other operations that show a social class gradient are? operations on the breast. These data include all breast surgery from biopsy to mastectomy. It is known that there is a positive social class gradient in the incidence of breast cancer, and the rate of detection $\bar{\Phi}$ of breast lumps, and therefore of biopsies, may be influenced by social class and education. Standardised consulting ratios show a $\frac{0}{3}$ clear gradient in consultations for both benign and malignant breast $\frac{\overrightarrow{ }}{\overrightarrow{ }}$ neoplasms, with women in social classes I and II consulting nearly twice as often as those in classes IV and V. ${ }^{15}$

The rates of vasectomy, sterilisation, dilatation and curettage, and hysterectomy are interesting in that they point to the importance of including data from the private sector when surgical rates are $\frac{\dot{\sigma}}{3}$ considered. The social class distribution of these operations is very. different if NHS surgery is considered alone as opposed to total rates, and in some cases the patterns are reversed. Standardised consulting ratios for menorrhagia, the most common indication for 음 dilatation and curettage and hysterectomy, show an inverse social $N$ class gradient that is consistent with the gradient for NHS surgery. ${ }^{15}$

In general, these findings are relatively reassuring for the NHS. These data provide no evidence to suggest that elective surgery is unequally distributed among the social classes within the health service, although there clearly were inequalities in the use of the common childhood operations in the 1930s to 1950s. They do, however, show a relatively high use of private sector surgery by the more advantaged social groups. It is not clear whether this is evidence of a greater demand for surgery from these groups. Bunker $\stackrel{+}{+}$ and Brown found a higher use of surgery among professional groups $\frac{0}{0}$ in the fee for service health system in California, ${ }^{16}$ and Bombardier et $\stackrel{\vec{D}}{\vec{d}}$ al found a positive correlation between surgical rates and income in $\frac{\rho}{\mathbb{D}}$ the United States, ${ }^{17}$ so this may be a feature of fee for service $\varrho$ systems. Scott and Mackie, however, who looked at surgical rates in Rhode Island, found only minimal differences between high and $\varnothing$ low income groups. ${ }^{18}$

The production of a surgical rate is the result of a complex interaction between various patient related and various health service related factors, and increased rates among higher social classes are not necessarily evidence of patient pressure. Although it 
is plausible that a determined patient can influence the decision in favour of surgery, it is also plausible that the same patient could successfully resist surgery that is recommended by the specialist. ${ }^{19}$ Similarly, increased rates among the more advantaged groups could be the result of differential selection by consultants or general practitioners or both and may not be evidence of direct patient involvement in, or influence on, the decision making process. Further research is clearly required before the relative influence on surgical rates of morbidity and clinical judgment, demand and supply, can be satisfactorily measured and the observed variations explained.

This study was funded by the Economic and Social Research Council. We thank the general practitioners and their patients, who kindly completed the questionnaires; also Nick Black, Geoff Bungay, Judith Challenger, Kate Hunt, Lesley Jones, Beryl Martin, Stella Mayers, Carolyne McKinlay, Janet McRae, Anne Reeve, Ros Thompson, Martin Vessey, Kay Yeates, and, in particular, Phil Strong.

\section{References}

1 Bunker JP. Surgical manpower. A comparison of operations and surgeons in the United States and England and Wales. N Engl f Med 1970;282:135-44.

2 Vayda E. A comparison of surgical rates in Canada and England and Wales. $N$ Engl $\mathcal{J}$ Med 1973;289:1224-9.

3 Fenton Lewis A. Morbidity data: what do we have? What do we need? What are we likely to get? Health Trends 1979;11:49-52.
4 McPherson K, Strong P, Jones L, Britton J. Do cholecystectomy rates correlate with geographic variations in prevalence of gallstones? Lancet 1984;ii: 1092-3.

5 McPherson K, Strong P, Epstein A, Jones L. Regional variations in the use of common surgical procedures, within and between England and Wales, Canada and the United States of America. Soc Sci and Med 1981;15:273-88.

$6 \mathrm{McPherson} \mathrm{K}$, Wennberg JE, Hovind O, Clifford P. Small area variations in the use of common surgical procedures: an international comparison of New England, England and Norway. $N$ Engl f Med 1982;30:1310-4.

7 Glover JA. The incidence of tonsillectomy in school children. Proc R Soc Med 1938;31:1219-36.

8 Calnan M, Douglas JWB, Goldstein H. Tonsillectomy and circumcision: comparison of two cohorts. Int $\mathcal{F}$ Epidemiol 1978;7:79-85.

9 Coulter A, Mcl'herson K, Elliott S, Whiting B. Accuracy of recall of surgical histories-a comparison of postal survey data and general practice records. Community Medicine 1985 (in press).

$10 \mathrm{Graham} \mathrm{H}$. Women, health and the family. Brighton: Wheatsheaf, 1984

11 Fox AJ, Goldblatt PO. 1971-75 Longitudinal study: sociodemographic mortality differentials. London: HMSO, 1982

12 Miller FJW, Court SDM, Walton WS, Knox EG. Growing up in Newcastle-on-Tyne. Oxford: Oxford University Press, 1960.

13 Anderson N, Cockcroft A, Murphy JF, Myers J, Panico S. Acute appendicitis and social class. $\mathrm{Br}$ f Clin Pract 1981;35:272-3.

14 Burkitt DP. The aetiology of appendicitis. Brf Surg 1971;58:695-9.

15 Royal College of General Practitioners, Office of Population Censuses and Surveys, Department of Health and Social Security. Morbidity statistics from general practice 1970-1971: socio-economic analyses. London: HMSO, 1982

16 Bunker JP, Brown BW. The physician-patient as an informed consumer of surgical services. $N$ Engl 7 Med 1974:290:1051-5.

17 Bombardier C, Fuchs VR, Lillard LA, Warner KE. Socioeconomic factors affecting the utilization of surgical operations. N Engl f Med 1977;297:699-705.

18 Scott HD, Mackic A. Decisions to hospitalize and operate: a sociociconomic perspective in an urban statc. Surgery 1975;77:311-7

19 Bloor M. Professional autonomy and client exclusion: a study in ENT clinics. In: Wadsworth M, Robinson D, eds. Studies in everyday medical life. London: Martin Robertson, 1976.

(Accepted 14 March 1985)

\title{
St Catherine's College Seminars
}

\section{The Warnock report}

\author{
MARY WARNOCK
}

The terms of reference of my inquiry were: "To consider recent and potential developments in medicine and science related to human fertilisation and embryology; to consider what policies and safeguards should be applied, including consideration of the social, ethical, and legal implications of these developments; and to make recommendations." Some general problems were posed by these terms of reference-for example, how widely were we to cast our net? What counts as a "potential" development? What in the future will still count as an "implication" of the use of new techniques? But we were first and foremost aware of the last injunction, to make recommendations. And so to some our report has seemed to be short on imagination and long on pragmatism. I would not dispute this judgment. It seemed to us the way we were obliged to go if we were willing to undertake the inquiry at all.

Another feature of the terms of reference was the distinction contained in them between medicine and science. While not believing that any such distinction could be exact or final, and while fully aware that advances in medicine must rely on advances in science, we nevertheless found it useful to divide our work into two

Based on a lecture given at this college on 11 February 1985.

Girton College, Cambridge

BARONESS WARNOCK, MA, BPHIL, mistress of the college parts, roughly following this distinction. We thus dealt, firstly, with problems related to the treatment of infertility and, secondly, with questions related to research. I will concentrate as far as possible on the second half of the report, which, though less exciting to the press and other media, is in my opinion by far the more important part. When we came to the question of research the problems facing the committee of inquiry were fundamental; and a solution to them, of some kind or other, needs most urgently to be found if we are to be able to plan for the future in certain extremely important areas of medicine.

\section{Use of embryos in research}

A first general point to be made is that there is a great danger at present that the issues, being difficult, will be widely treated as easy-indeed, as a matter of rhetoric. There are those who appeal to moral principles in the matter of research without really thinking very clearly whether these principles, if adopted, would or would not preclude the use of early embryos in research programmes. And since it is always more agreeable to think in simple than in complicated terms, and since moral indignation is one of the most delightful of passions to indulge in, I believe that there is a real danger that the indignant will win the day and all research using human embryos will be brought to an end. Those who believe in the need for this research have a duty to argue their case as widely, but also as intelligently, as possible.

The second general point is that, as the law stands at present, human embryos, whether in vivo or in vitro, are not fully protected 